\title{
MEANING-MAKING OF INTERNET MEMES TO CREATE HUMOROUS SENSE: FUNCTIONS AS SPEECH ACTS
}

\author{
Fatma Rahayu Nita, Slamet Setiawan, Lies Amin Lestari \\ Universitas Negeri Surabaya, Surabaya, Indonesia \\ E-mail: slametsetiawan@unesa.ac.id
}

Received: 2021-10-15

Accepted: 2021-11-16

\begin{abstract}
This research explored how the memes were created with multimodal elements that could make meaning to create a humorous sense and function as speech acts. With the complexity of meaning-making, nowadays, it had become a trend that people could communicate online through Memes. Semiotics provides how the combination of modes, media, and potential meanings, that were applied to make meaning in memes. At the same time, pragmatics proposes details on how memes can function as speech acts. This research adopted a qualitative method using multimodal analysis by Leeuwen (2005) and speech acts theory by Bach and Harnish (1980) that were employed as the theoretical framework. A total of 16 memes were retrieved and captured as JPG files from social media and other internet websites; therefore, documentation was the only technique used in this research. The results of the study showed that (1) the integration of semiotic resources such as mode, media, and meaning potentials in memes aided the readers to understand the background knowledge of memes (2) two types of communicative illocutionary acts were found in the memes: constative and directive illocutionary acts which function to express the emotion or opinions and question something (3) the effects of using internet memes could be seen through verbal and nonverbal perlocutionary acts which showed an agreement and had the same feeling as in the memes. Finally, the memes containing multimodal components composed of semiotic resources interacted creatively to make humorous sense, and it could aid the readers to communicate online.
\end{abstract}

Keywords: internet memes; multimodal; semiotic resources; speech acts; humour

\section{Introduction}

The terms memes and gifs should be familiar to the users in social media platforms because they are not modern terms. Dawkins (1989) produced a book called Selfish Genesat and found the name in 1979 (Börzsei, 2013; Milner, 2012; Shifman, 2014). Meanwhile, Börzsei $(2013$, p. 3) asserts that Richard Dawkins built the label 'meme' from the Ancient Greek word. It is 'mimēma' that denotes "somewhat copied." Dawkins (1989) talks over dual extents that evolutionary theory distinguished between memes and genes. He recognizes that consideration of human nature arises from culture. Dawkins' authentic uses the term of meme to point out thoughts, games, catchphrases, faith, language, etc. (Milner, 2012). Davidson (2009, p. 122), further, claims that a precise definition for the modern concept of the internet meme is lacking. Consequently, he employs new descriptions to describe 
Meaning-Making of Internet Memes to Create Humorous Sense: Functions as Speech Acts, Fatma Rahayu Nita, Slamet Setiawan, Lies Amin Lestari

internet memes as part of a culture, typically jokes receiving impressions through online communication.

Memes standing for Internet memes which consist of humorous sense, are described as witty, multimodal, digital stuff, user-generated with typical content features, created with a consciousness of each other and shared, imitated, and modified by internet users (Shifman, 2014). Milner (2012) specifies internet memes as media artefacts that are widely compounded and redistributed by other uses on social media. The definition accords with several levels of thoughts conveyed within theories of multimodality, semiotics, which are discussed in the current study. This recent study refers to the term meme that was proposed by Dawkins (1989). Chovanec and Tsakona (2018) state that nowadays, the trend in online humour is using multimodality. Internet texts that consist of humour serve creative mixtures of linguistic and semiotic components. Amid the categories that emerge in digital communication, internet memes have gained academic attention because they have been shared in many digital platforms. This recent study explores the multimodal analysis of the latest internet meme in 2021 is obtained from social media such as Twitter, Instagram, and other platforms.

Apart from the explorations of multimodal analysis, this paper proposes a new way of analyzing memes seen from multimodal and pragmatic analysis. Scholars note that internet memes are shared to invite involvement among users (Börzsei, 2013). Memes analysis is indispensable since memes are quite viral and applied to online communication. Communicating with other people reveals that people employ speech acts to understand the message based on the context. In the past, speech acts were connected to spoken communication; however, nowadays, it could be applied in written texts, in this case, memes. Memes could include text or images, such as facial expressions, gestures, body language, etc. These are commonly known as reaction shots in which memes are non-verbal communication (Grundlingh, 2017). Sebeok (2001) asserts that from the perspective of semiotics, verbal sign and non-verbal systems have to be incredibly intertwined and link one another through each character's life. Speech act theory involves pragmatics, while semiotics proves that non-verbal communication might be construed similarly to verbal communication. Therefore, non-verbal memes could be regarded as a speech act since the receiver grasps the context of the message (Denisova, 2019).

A number of studies on internet memes have increasingly developed in recent years. The studies mainly explored the memes seen from the cultural logic (Shifman, 2014), the language used in memes (De la Rosa-Carrillo, 2015; Laksono \& Putranti, 2016), certain forms of linguistic humour seen from multimodal interactions (Vásquez \& Aslan, 2021), and the combinations of textual and visual meaning-making ( Yus, 2019; Jiang \& Vásquez, 2020). Those studies mainly address particular perspectives, whether seen from the language found in memes or multimodal analysis. Yet, only a few studies reveal internet memes as speech acts and examine them based on meaning-making. To date, one of the scholars, Grundlingh (2017), made an effort to introduce a new approach in which memes could be linked to speech acts and examined through the use of multimodality and semiotic resources. In such a case, this current study attempts to extend the earlier work of Grundlingh (2017).

A dearth of previous researches still combines speech acts and multimodal analysis in one body of research. Consequently, this research forms an innovative approach to memes. It investigates internet memes using key theories from semiotics and pragmatics, which have not been discussed in the studies mentioned earlier. Since memes come up with complex communication affordances to deliver meaning and create humour, the multiple levels of 
intersection between linguistic and visual in memes gain additional significance. Seen from the studies mentioned above, this research offers a distinctive analysis of meaning-making in internet memes to interpret text-image combinations and how they work together to create humorous meanings. With this background in mind, this research proposes the subsequent research questions: (1) How do semiotic resources communicate to create meaning-making of internet memes? (2) What are the illocutionary acts found in internet memes to create a humorous sense? (3) How are the effects of memes on internet users?

\section{Literature Review}

\subsection{Multimodality}

Nowadays, multimodality is gradually more prominent because of the spread of discourses on the internet that merge various modes such as pictures, audio, text, and video. The notion of multimodality was spread at the beginning of the $2000 \mathrm{~s}$. With the efforts of Halliday, who viewed language as a social semiotic system, Jewitt (2013) stated that Halliday's effort shifted the focus of language as a static linguistic scheme, then considered language as a social scheme. Further, Jewitt (2013) views multimodality as an interdisciplinary approach derived from semiotics resources that understand interaction and depictions outside of language and seeks a systemic social interpretation of various forms of meaning. In general, multimodality appeals to how multimodal texts are shaped and how semiotic resources: colour, framing, position, and focus of elements perform to form the meaning.

As explained in the introduction that memes are described as media artefacts created and shared across all online platforms consisting of semiotic sources such as modes and media, and all of these modes have diverse functions and uses. Jewitt (2013, pp. 251-252) states that meaning in the mode is interconnected with the senses formed by other modes to work together to make successful communication. A relation between modes contributes to the construction of meaning. Jones $(2013$, p. 1) denotes Scollon and Levine (2004) when differentiating mode and media. A mode could be defined as a semiotic scheme with core grammaticality, such as colour, speech, design, and taste, and media is seen as the physical modes, such as television, computer screens, telephones, and paper.

\subsection{Semiotic Resources}

The term 'semiotic resource' is primary used in social semiotics. It stems from the work of Halliday, who states that grammar is neither a set of rules nor a code for building proper sentences, but elements for meaning-making (Halliday, 1978, p. 192). Leeuwen (2005, p. 285) states that semiotic resources function as the resources and objects utilized to communicate. Furthermore, he argues that meme takes a meaning potential as the primary semiotic resource. Practically, meme is produced to reveal something. It can be directed to express a feeling or to deliver idea. Besides, memes can be constructed to utter the purpose to apologize and address an inquiry. Suppose the memes are shared on the internet and social networking sites. In that case, meme analysis is highly contingent on the memes' background knowledge, purposes, and use by the diverse internet users. Types of memes, such as reaction shots, can be taken as an example, that contain no text. It recognizes the recipient or reader should analyze the meme based on the context due to the absence of the texts. This kind of reader refers to what Eco (1979) described as a "model reader."

Further, Eco (1979) states that the writer must predict the model reader of the recipient, assumedly, those who can interpret by using the similar expression to the writer 
Meaning-Making of Internet Memes to Create Humorous Sense: Functions as Speech Acts, Fatma Rahayu Nita, Slamet Setiawan, Lies Amin Lestari

who deals with them. It should be noted that there is a distinction between signification and the communicative process. The communicative process can be described as the portion of the signal obtained from the source to the destination. When the goal is human, it only conveys some information that occurs. However, if the basis is not human, the sign is the only inducement that produces an informational answer in the recipient, defined as the signification process. This process occurs due to the availability of the code. A code is primarily a tagging system that can be used to provide entities with non-existent units. Thus, memes can be interpreted as a signification process. Since memes are described as multimodal artefacts that can also be analyzed from semiotic theory, they have the potential to have messages that are more complex than just ordinary images that are shared from one person to another. Notwithstanding, signification and speech acts' theory are considered in two distinct research fields; both pragmatics and semiotics aid in making a clear concept of how memes are utilized for communicating.

\subsection{Speech Acts (Locutionary, Illocutionary, and Perlocutionary)}

Speech acts are involved in the theory of pragmatics. Yule $(2006$, p. 112) defines pragmatics as studying what utterers mean. The communication relies upon admitting the meaning of words in a statement and realizing what utterers mean by their statements. Austin (1962) stated that the utterance could be implemented to do an act. For instance, if people address a sentence, it is not merely saying something, but people might also perform something such as creating a commitment, making an apology, etc. (Schiffrin, 2005, p. 31). Austin (1962) expanded a trichotomy to differentiate the various speech acts: locutionary, illocutionary, and perlocutionary acts. The locutionary act can be explained as the construction of words and speech creation. The illocutionary acts have to do with performing one of language purposes: the act of saying words or things. The perlocutionary act forms the special effects, whether intentional or unintentional, to say and do something (Austin, 1962). There should be an effect that influences the reader's thoughts when the speaker offers the idea.

Bach and Harnish (1980, p. 40) propose six kinds of illocutionary acts, four of which are constative, directive, commissive, and confessional. Constative expresses that the speaker's ideas and intentions have the same idea as the listener. The directive denotes the speaker's attitude toward the listener's upcoming actions and his purpose that he utters, or the attitude he expresses is carried out as a reason for the listener's action to accept the utterance. Commissive conveys the speaker's intention and belief that his statement requires him to do something. Recognition expresses feelings about the listener, the speaker's meaning that his utterance meets social expectations to direct certain feelings and beliefs about what is being done. It is in line with several points about illocutionary acts proposed by Austin (1962) and Searle (2002). The four main illocutionary acts introduced by Bach and Harnish (1980) are communicative. Two different illocutionary acts are effective illocutionary acts and decisions, which are considered conservative. The conventional illocutionary acts could be explained as selecting, resigning, arresting, releasing, marrying, baptismal, etc. This research only uses communicative illocutionary acts because it fulfils memes as illocutionary acts. Successful communication can occur if the recipients of the message realize the illocutionary acts. The utterance is made explicitly or implicitly to understand the following conversation (Shifman, 2014). Communication could be verbal or non-verbal (body language, gestures, etc.). In this case, memes can be involved in non-verbal 
communication. Several factors influence how the recipient realizes a speech act, either verbal or non-verbal-the addressee recognizes a speech act and responds appropriately.

\subsection{Memes Function as Speech Acts}

Despite the possibility that all types of memes can be considered as speech acts, it has been validated by several studies that some types of memes are more accessible to construct than others and are also used with greater frequency. In this research, two specific types of memes will be examined to explain how these types of memes can be defined as speech acts. Milner (2012, p. 85) categorizes 13 kinds of memes. For 13 (thirteen) kinds of memes are split into remixed images and stable images. The remixed images are divided into single pictures and stacked pictures. Below is the classification which is adopted from Milner (2012, p. 85).
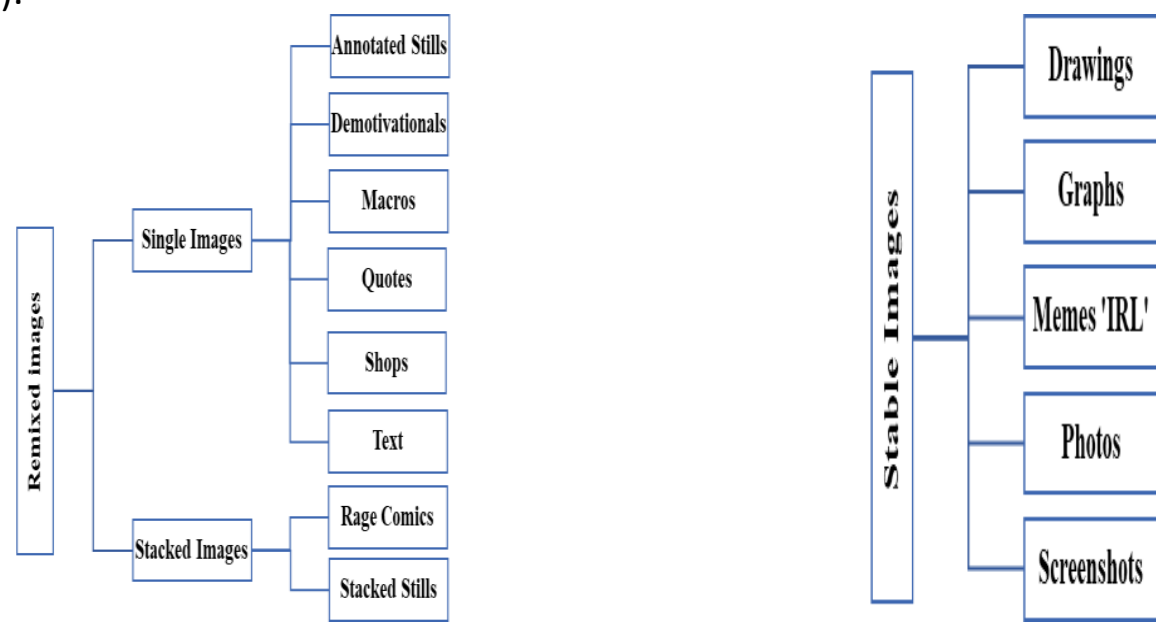

Figure 1. A Classification of Meme Collectives (Milner, 2012, p. 85)

This research focuses on remixed images which consist of single images and stacked images. It contains annotated stills, demotivational, macros, quotes, shops, and text for single images. Meanwhile, the stacked images involve rage comics and stacked stills. Single images are remixes that emerge on a single frame. Stacked images blend several single images into a new set of pictures frequently to create a more complex meme. Annotated images mingle with the text, creating addendums, appending dialogue bubbles, etc. Demotivation combines image and text in a satire of 'motivational' posters framing images in black squares. There are also two levels of white text: the main clause is positioned in a larger font size above the supporting clause. Image macros are the most typical artefact collected for this research - apply text within the image, often a clause at the top of the image to set up a premise and a clause at the bottom to convey interesting lines. Images and text also mix into quotes in a collection of memes, often combining a statue of the quoted character with the text of the quote. Shop means creating a new image by combining elements from several other images. The shop can also add effects such as changing the colour of the image. Lastly, sometimes image files ignore images completely that shares only graphic text. However, these texts are still images and often blend the same multimodal meme aesthetic. Rage comics are built from a well-established collection of angry faces and texts. Stacked stills take macro photos or annotated photos and combine them into a multipanel image (Milner, 2012). 
Meaning-Making of Internet Memes to Create Humorous Sense: Functions as Speech Acts, Fatma Rahayu Nita, Slamet Setiawan, Lies Amin Lestari

\section{Research Method}

This research is under qualitative study that explores how memes can be analyzed through the theory of pragmatics by Bach and Harnish (1980) and semiotics by Leeuwen (2005). It provides a distinctive analysis of meaning-making in internet memes to interpret the text-image combinations and work together to create humorous meanings. The data are in the forms of images, words or phrases, and sentences. The data source is social media, especially Instagram, Twitter and other internet websites; therefore, documentation is the only technique used in this research. It chooses Instagram and Twitter because Internet users are likely to post memes and communicate through memes to create humorous senses in those platforms.

A total of 16 memes were retrieved and captured as JPG files. Data were gained from Twitter ( $N=7)$, Instagram ( $N=3$ ), and other websites $(\mathrm{N}=6)$ from April to June 2021. The study is concerned with two types of memes, notably image macros and stacked stills, regarded as speech acts. The responses to the memes posted are also obtained and analyzed in this research. The selected memes are chosen randomly and are then analyzed based on the multimodal theory focusing on semiotic resources utilized in the memes and speech acts theory that concerns illocutionary acts. Moreover, it reveals how internet users communicate in social media through memes that are examined through the perlocutionary acts, which could be seen through the comments that appear in the memes.

\section{Results and Discussion}

The analysis of the data is divided into some categories to represent any type of meme. The results of the first, second, and third research questions are intertwined with another; therefore, it combines the analysis of those three research questions. As already mentioned in the literature review, the listener should interpret the speaker's intended meaning appropriately to succeed in the illocutionary act. The example of stacked images can be seen as following:

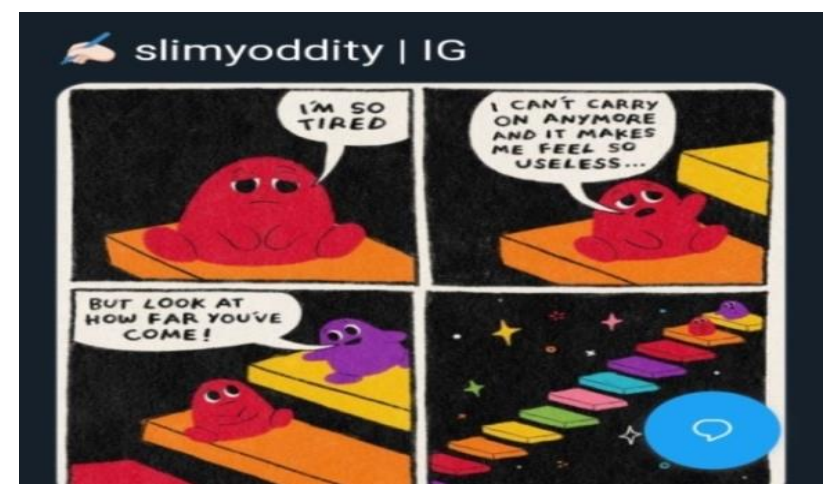

Figure 2. Example of Stacked Stills (https://slimyoddity.com)

Figure 2 consists of pictures and text that are remixed into quotes in the meme. This meme combines characters' facial expressions, text, various colours, and the black background of the image to make meaning. The characters are blobs: the red is called Slimy, and the purple one is named Oddity. The two main characters represent Cherie and her partner Tim correspondingly. In the comics, it discovers that Oddity is continuously imposing truth bombs on Slimy all the time. Those two blobs are created to represent the experience of each individual. Thus, in Figure 2, the texts state and tell the reader that Slimy is so tired and cannot carry on anymore. In such a case, the meme's purpose is to advise the readers; 
thus, the meme involves an illocutionary directive act. Yet, the Oddity responds to Slimy, "how far you have come!" The response is such a piece of advice to Slimy and reminds the readers about what has been done. The last picture shows the steps being reached by the Slimy. Therefore, it is a kind of reflection toward the model reader. If the model readers experience that feeling, they will respond to the memes. The representations of different reactions are shown as following:

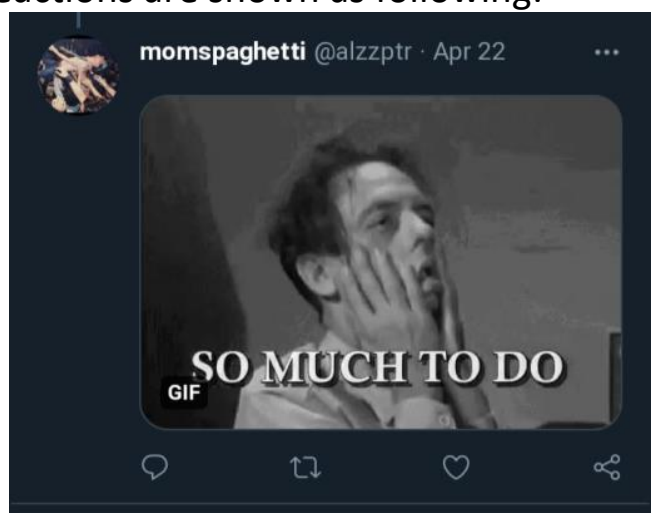

Figure 3. Example of Comments

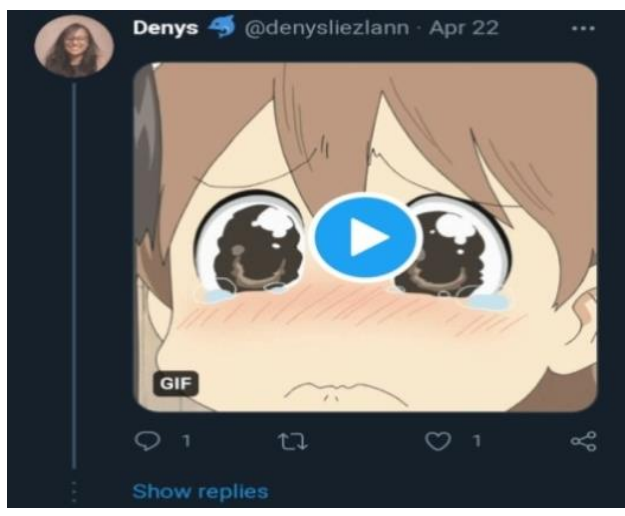

Figure 4. Example of Comments

Concerning the third research question, this part shows the reactions of internet users, as seen in Figure 3 and 4. They show that they understand the memes' context. Figure 3 employs both image and text, while figure 4 does not include text. With the expression of sadness, the users try to express their feeling through uploading images with the sad reaction. Through non-verbal language, internet users attempt to define the unfortunate sense. It proves that the memes posted by the users affect other Internet users. With memes that combine mode and media employed in the picture, the memes also have a role as speech acts. It shows how the reader of memes also sent the reaction towards the memes that indicate perlocutionary acts successfully. other memes that also suggest speech acts and combines semiotic resources are also presented as follows:

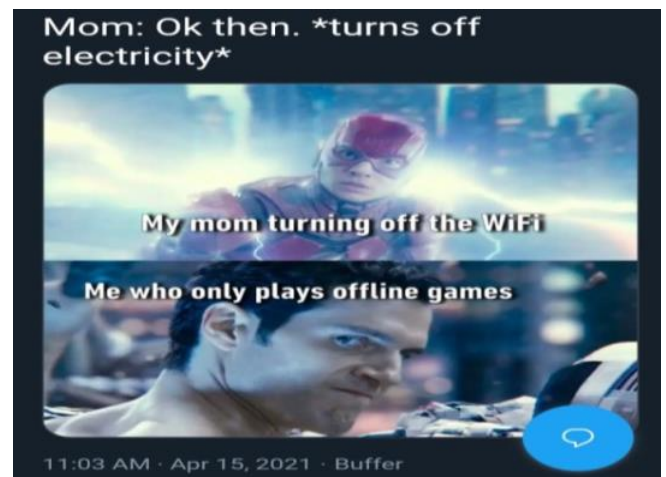

Figure 5. Example of Stacked Stills (www.twitter.com)

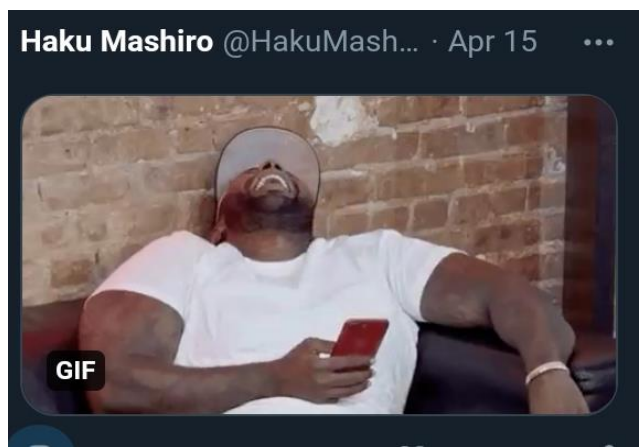

Figure 6. Example of Comment (www.twitter.com)

A single image macro is simply a collection of one-way memes that use images and text to comment on the world. In vital derivatives, while macros are stacked with other images, they become still stacked and read like comics (Figure 5). This comic is a basic example of the so-called vertical meme collective, a common type of still image. In this vertical, the image of an English actor named Henry Cavill, who becomes DC comics character Superman is stacked on top of a picture as in character in a flash. The flash is the name of some fighters acting in 
Meaning-Making of Internet Memes to Create Humorous Sense: Functions as Speech Acts, Fatma Rahayu Nita, Slamet Setiawan, Lies Amin Lestari

American comic books published by DC comics. The flash shows the plain expression while Henry Cavill presents his facial expression of upset. These stacked stills offer two different pictures with different facial expressions. This meme contains the image and the texts that successfully create a humour sense toward other internet users. The texts are statements; thus, it involves in constative illocutionary acts. The meme encourages the reader to respond to the meme. The representations of their reactions are served below:

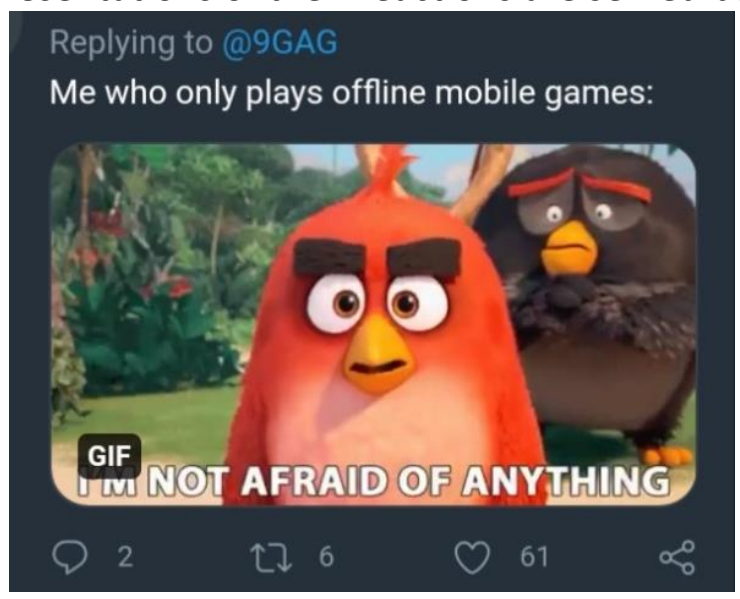

Figure 7. Example of Comment

There are some reactions by Internet users in responding to the memes. It takes only two images that have different types of memes: image macro and reaction shots. Figure 6 is an example of reaction shots since it only presents the image without the text. In such a case, the idea of a model reader must be fundamental. An internet user posts a meme as a comment since he or she may experience the same thing as the meme posted by the creator. Thus, the comment in Figure 6 indicates that the reader understands the meme creator's intended meaning. Through the laugh expression, it is believed that the readers know the information suggested in memes. The second comment is an image macro because there is an image and the text underneath the image in the macro (Figure 7). It employs the image of angry birds (Red and black characters) with the standard expression. It presents the reader's expression towards the meme. The text, "I am not afraid of anything", indicates that she or he might not be afraid of what her or his mom is doing. In this context, a meme is regarded as speech act since there is an interaction between internet users through memes. The followings are other examples of the memes that present the special issue of covid-19:

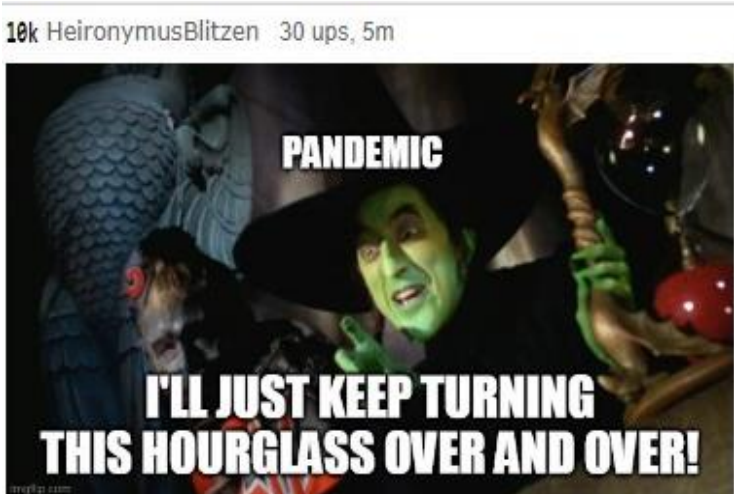

Figure 8. Example of Image Macro

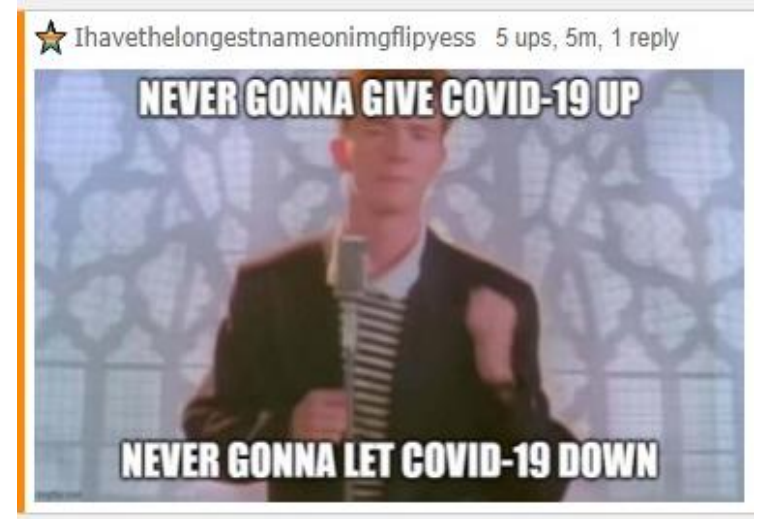

Figure 9. Example of Comment 


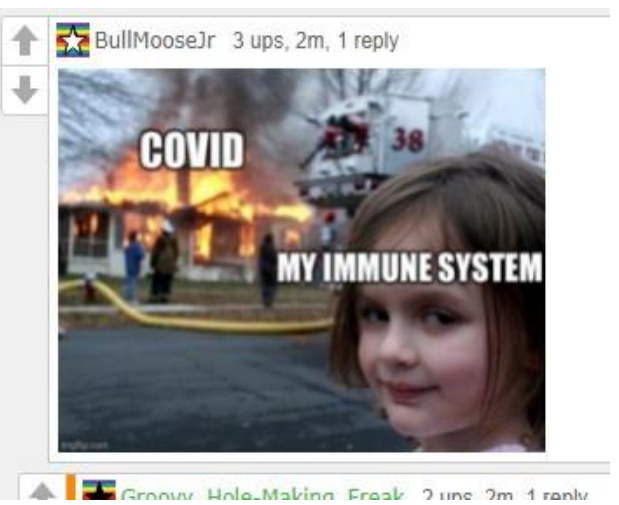

Figure 10. Example of Image Macro (https://imgflip.com)
竞 Lamejokey 1 up, $2 \mathrm{~m}$

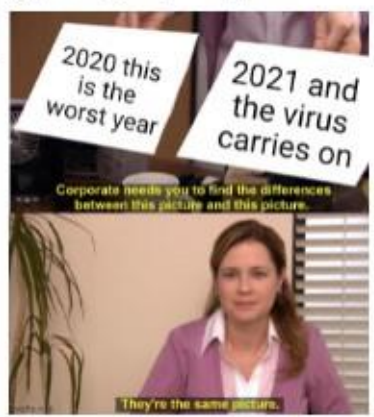

Figure 11. Example of Comment (https://imgflip.com)

Figure 8 consists of one image and the texts caption both below and top of the image. The textual elements emerge in block style; the fonts are all caps with white colour. It is such an example of an image macro found on an Internet website. For the context, it is related to the current issue, which is covid-19. The creator states in the caption, "I will just keep turning this hourglass over and over". She or he attempts to create a joke concerning the pandemic issue that is still not over yet. It employs a green-skinned girl who is the fictional character in the wicked witch of oz. The facial expression is sick of the situation that coronavirus is still not over yet. Through a meme, she or he can express the idea and communicate with other internet users. The illocutionary found in this meme is constative since it only states the belief. Yet, the facial expression, the text, the image aids the readers to interpret the intended meaning of the meme. The response of another user (Figure 9) indicates that the reader could understand the meme since it writes a current issue that everyone may know about it. The reply by another user employs the same type of meme, which is image macro. It has been discovered that image macro is frequently found in memes. Figure 10 has the same issue, covid-19. Yet, it has a different meaning potential from Figure 8. Figure 10 attempts to advise internet users that people should have good immune systems in this pandemic era. With the combination of images and texts, several comments are given to the memes. Yet, only one comment is taken as an example (Figure 11). A type of meme is included in stacked stills since it employs two pictures in one meme. The user expresses the feeling by saying that 2020 is the worst year due to the coronavirus. Therefore, this meme, the image macro, is used to joke and express something related to the current issue, which is covid-19.

Another image macro that is created to make humour related to daily life is shown in Figure 12. It consists of one character merged in one picture with different texts and different expressions. The character employed as the central figure is Hank Schrader. He is one of the fictional characters in the AMC drama series Breaking bad, and its spin-off series better-called saul. The combination of texts and facial expressions in the image macro are presented to create meaning-making. Thus, the meme has the potential to express emotion related to a student's daily life. On the left side, the sad expression denotes the student's homework, while the right side, the happy one, is shown when the students have a good weekend. The illocutionary act could be identified through the image caption, which is a constative one. The meme has successfully addressed the reader through the combination of texts and facial expressions. Many internet users respond to the meme. Some comments are presented in Figure 10. The internet users do not employ memes, but they respond to 
Meaning-Making of Internet Memes to Create Humorous Sense: Functions as Speech Acts, Fatma Rahayu Nita, Slamet Setiawan, Lies Amin Lestari

the meme with the texts since the meme is uploaded on Instagram, where the comments box is text. One of the internet users understands the background of information of the image by commenting that "hank is a good example of dedication". Knowing the context encourages internet users to give comments to the meme due to its humour. It is believed that memes aim to create humour and to perform other illocutionary acts.

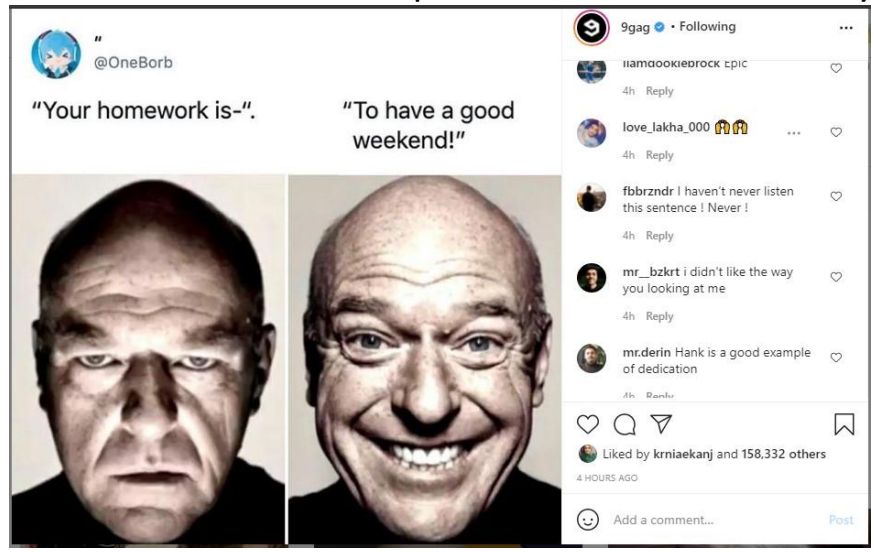

Figure 12. Example of Image Macro (https://www.instagram.com/?hl=en)

Another purpose of memes, to ask a question, is presented in Figure 13 and 14. Memes address questions or questions that often insert humour cannot always be seen as serious questions. The controversy may occur when some of the creators address the questions. The questions in memes are not only about a specific topic. A standard image macro (Figure 13), Obi-Wan Kenobi is an imaginary character in the Star Wars franchise used as the central figure in the meme to ask questions. In such a case, the illocutionary acts found in this meme can include constative and directives. The meme gains several responses from internet users, as seen in Figure 13. As seen from the comments (Figure 14), the internet user understands the background knowledge of the memes. One of the internet users responds, "My dad is nearly 50 and plays halo/cod and watches starwars cartoons". It shows that she or he recognizes the character employed in the meme by mentioning Starwars cartoons. Form the comments; they all try to relate the memes to themselves. Most of them show an agreement towards the memes. Therefore, memes facilitate internet users to communicate online.

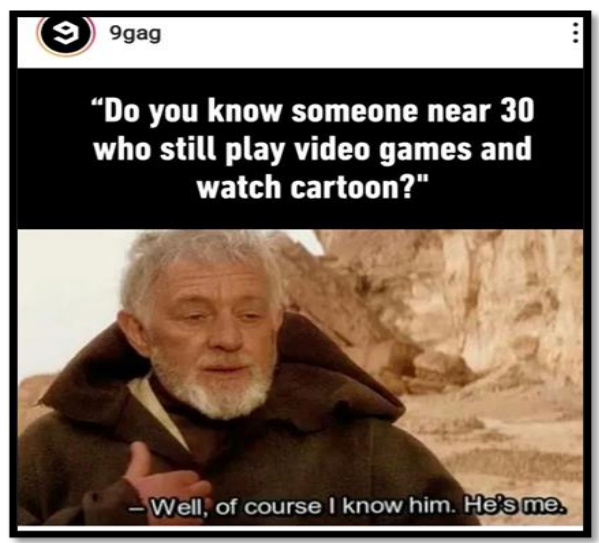

Figure 13. Example of Image Macro https://www.instagram.com/?hl=en)

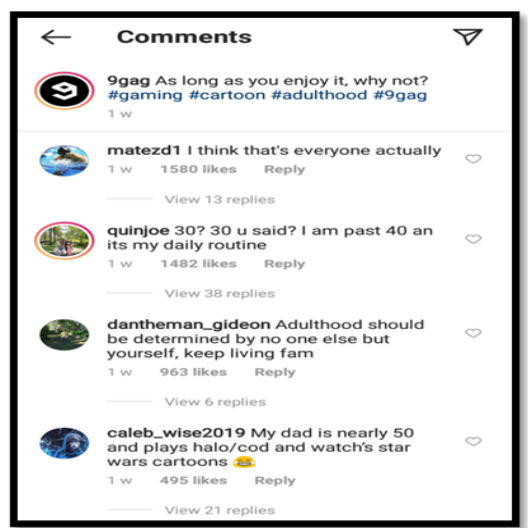

Figure 14. Example of Comments (https://www.instagram.com/?hl=en)

Another example of a meme that creates humorous sense through question could be seen in Figure 15: 


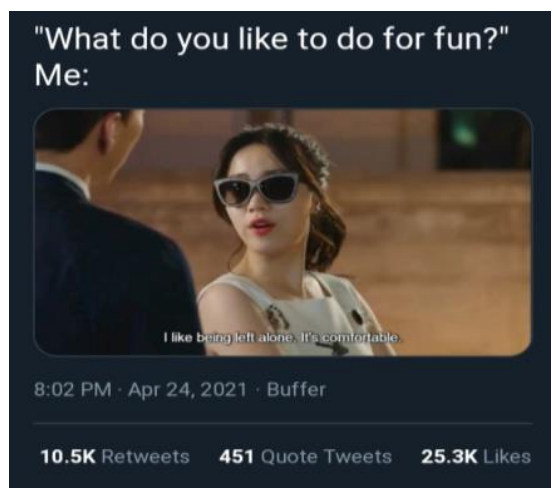

Figure 15. Example of Image Macro (www.twitter.com)

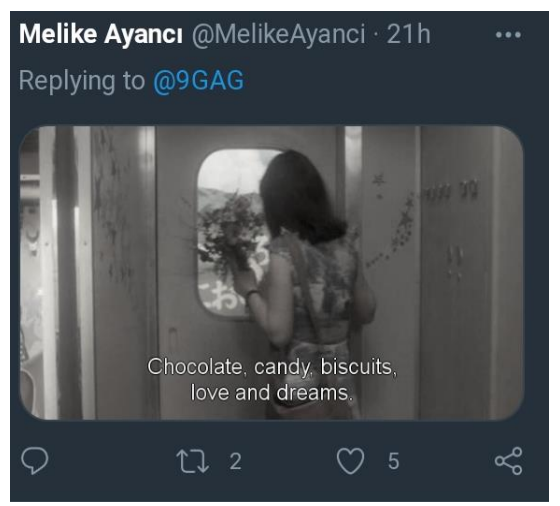

Figure 16. Example of Comment (www.twitter.com)

It shows how memes could be used to respond to the question. Before displaying the image, the meme creator asks the question. Then, the answer is in the form of a meme. This meme is a single image with its text merged in the text. The character displayed in the meme is Ryu Hwa-young, one of the South Korean actresses and singers who becomes a South Korean group named T-ara. This character represents how young ages nowadays are impressed by Korean dramas. Thus, the selection of the character is not without reason. This kind of meme has meaning potential to make a joke. A constative illocutionary act is found in this meme since it attempts to express the idea or opinions of something. Several responses toward the meme are detected, yet one example (Figure 16) shows that the readers try to answer the question addressed by the meme creator using an image macro. It is believed that internet users employ memes to communicate online.

From the analysis above, it can be drawn that two types of memes: stacked stills and image macro are commonly found in the memes which function as speech acts. These memes employ several characteristics of semiotic resources such as meaning potentials, mode, media which aid the readers to understand the background knowledge of memes. The combination of multimodality found that there are two types of communicative illocutionary acts: constative and directive illocutionary acts, which function to express the emotion or opinions and question something related to emotions for daily experiences and everyday situations. From the illocutionary acts found in memes, there is also an effect that influences internet users to react toward the memes. The responses are in the form of verbal and non-verbal perlocutionary acts. Most internet users share the same experience and feeling as the meme creators and show their agreement towards the meme posted. Therefore, in this research, the memes containing multimodal components composed of semiotic resources that interact creatively to make humorous meanings, and it can aid the readers to communicate online easily. In this case, this research argues that memes, especially stacked stills and image macros can function as speech acts.

\subsection{Memes as Speech Acts}

Refers to the results of the previous studies displayed in the literature review; this research detects three points of memes that are interesting to discuss: the semiotic resources used in the memes, the types of illocutionary acts found in the memes, and how the combination of semiotic resources and illocutionary acts can affect other internet users, which can be seen through the comments. Thus, this research discovers two kinds of memes that function as speech acts: stacked stills and images macros. It is in harmony with the 
Meaning-Making of Internet Memes to Create Humorous Sense: Functions as Speech Acts, Fatma Rahayu Nita, Slamet Setiawan, Lies Amin Lestari

study by Milner (2012, p. 89), who asserts that image macros are not merely the most common type of memes but also vivid illustrations of the interplay of transformation and imitation in the process that leads to memes. Besides, both could be the representations of memes that function as speech acts.

Firstly, concerning multimodal analysis, the findings indicate that memes combine the script, the facial expression of the characters, the various colours, and the black background of the image to make meaning (Figure 2). Combining semiotic resources in memes such as media and mode can create a humorous sense in memes. Leeuwen $(2015$, p. 447$)$ states that various semiotic modes include language and pictures conjoined and incorporated into a presented discourse or kind of speech. This finding also corresponds to Milner (2012, p. 11), who states that memes are applied in culturally mediated participation networks for multimodal artefacts in which images and text integrate to make jokes, observations or convey arguments. In this research, the combination of images and text convey a joke or create a sense of humour. The previous research done by Yus (2019) has proved relevant theory to realize the clarification of image macros based on the composition of multimodality.

Applying relevant theory to online text interpretation, Yus $(2019$, p. 107) displays that the intended meaning of the meme cannot be gained from the incomplete purposes of text or picture which is taken independently, but only from their conjoined goals that result in implications. In this case, the meaning of a meme can only be construed by recognizing the connotative meanings of the text, image, and the combination of text and image. Yet, the findings argue the claim by Johann \& Bülow (2019) that the visual mode in the meme is the most important than others. Besides, one of the essential characteristics used in memes is meaning-potential (Leeuwen, 2005). It discovers that each meme is designed to reveal something. It can be emotion as in Figure 2, Figure 5, Figure 9, Figure 10 or an opinion as Figure 8. Memes can also be created to reveal the intent to offer a question (Figure 12). The memes as meaning potential express opinions or emotions (Leeuwen, 2005, p. 285). The findings are supported by Davidson (2009, p. 127) that similar memes can employ various texts to show multiple purposes, such as giving advice, creating humour, and expressing emotions. Denisova (2019) and Wiggins (2019) reveal that internet memes mainly express feelings or affect, for example, rage, joy, anger, and excitement in reaction to real-world events.

Secondly, as the aims of this research, only image macros and stacked stills are analyzed. It discovers two types of illocutionary found in two kinds of memes. They are constative (Figure 5, 8, 12, 13, 14) and directives (Figure 2, 13). These findings align with a previous study done by Grundlingh (2017). It states that constative and directive illocutionary acts are commonly found in memes. Bach \& Harnish (1980) proposes two types of illocutionary acts: commissive and acknowledgement, that are not found in this research. Grundlingh (2017) alleges that since memes are unique way to interact, it is clear that the memes' function cannot parallel with all the communicative illocutionary acts.

Yet, memes could be made for particular and individual purposes. In such a case, a meme can be used to thank someone or congratulate other people. It is also possible that memes are employed to beg a person to do something, ask someone to perform an act, and forbid someone to do something. It discovers in this study that memes can perform speech acts. Internet users employ memes to express something (Figure 2, 8, 12 and comment on the memes (Figure 3,4). This finding correlates to Grundlingh (2017) that a particular meme is employed to comment on the utterances. The comments are given because several 
internet users understand the background knowledge of the memes. This aligns with Shifman (2014) that successful communication can occur if the message recipients realize the illocutionary acts. It is emphasized by Bach and Harnish (1980), it is vital for the hearer to know the contexts and recognize the intention to communicate successfully. The findings show that the memes shared by the creators gain more responses from other internet users. It links to the previous study by Börzsei (2013) that internet memes are distributed and call participation to give answers, encouraging to write a text related to the memes shared.

Lastly, internet users can communicate on social media through memes. It could be examined through the perlocutionary acts. The findings show that other internet users react toward the memes through verbal and non-verbal perlocutionary acts. Verbal perlocutionary acts are shown in Figure 12 and Figure 14 that present an agreement toward the memes posted. It is in line with the previous study by Wahyuningsih \& Nirmala (2020) that the effect that may appear shows an agreement. Besides, non-verbal perlocutionary acts can be seen in Figures 3, 4, 6, 7, 9. It is in signs such as smiling, laughing, body language and other facial expressions. Another response is by uploading reaction shots. This finding is harmonious with Milner (2012, p. 96), who mention that reaction shots are employed when the macro aims to represent a social sign that responds during a conversation. This study recognizes the fact that speech acts can be verbal and non-verbal as well. It is inferred in specific contexts without the use of spoken or written words. As seen in Figures 12, 14, the responses are in the form of conversation. It indicates that memes can function as speech acts. If a recipient cannot acknowledge the speech act (illocutionary act), communication does not happen successfully since understanding the speech act supplies the recipient with practical constraints for the reply (Grundlingh, 2017).

\section{Conclusion}

From the explorations above, three points can be highlighted based on research questions. First is the integration of semiotic resources such as mode, media, and meaning potentials in memes to aid the readers to understand the background knowledge of memes. Second, two kinds of memes: image macros and stacked stills represent memes that function as speech acts. Meanwhile, there are two types of communicative illocutionary acts found in the memes: constative and directive illocutionary acts, which express the emotion or opinions and question something related to emotions for daily experiences and everyday situations. The last point is related to the illocutionary acts found in memes. There is also an effect that influences internet users to react toward the memes. The responses are in the form of verbal and non-verbal perlocutionary acts. In this research, the memes containing multimodal components composed of semiotic resources interact creatively to make humorous meanings, and it can aid the readers to communicate online easily. In this case, this study argues that memes, especially stacked stills and image macros, can function as speech acts.

There is a wide-ranging study on humorous memes but the study concerning pragmatic analysis is hardly found. Thus, this research explores memes seen from pragmatic and multimodality analysis. This study only concerns two types of memes: image macros and stacked stills, which can function as speech acts. Based on the results of this research, further research could shed light on the other humorous memes connected to digital genres, such as Graphics Interchange Format (GIFs). It also includes a few seconds of an emotionally charged media moment and covers multimodal play. It is also possible to identify other kinds of memes that internet users use to communicate online. 
Meaning-Making of Internet Memes to Create Humorous Sense: Functions as Speech Acts, Fatma Rahayu Nita, Slamet Setiawan, Lies Amin Lestari

\section{References}

Austin, J. . (1962). How to Do Things With Words. Cambridge: Harvard University Press.

Bach, K., \& Harnish, R. M. (1980). Linguistic Communication and Speech Acts. Massachusetts, MA: The MIT Press. https://doi.org/10.2307/413908

Börzsei, L. K. (2013). Makes a Meme Instead: A Concise History of Internet Memes. New Media Studies Magazine, 7(March), 1-29.

Chovanec, J., \& Tsakona, V. (2018). Investigating the Dynamics of Humor: towards a Theory of Interactional Humor. In The Dynamics of Interactional Humor: Creating and Negotiating Humor in Everyday Encounters (pp. 1-26). John Benjamins.

Davidson, P. (2009). The Language of Internet Memes. The Social Media Reader, 120-134.

Dawkins, R. (1989). The Selfish Gene (2d ed.). New York: Oxford University Press. https://doi.org/10.4324/9781912281251

De la Rosa-Carrillo, E. L. (2015). On the Language of Internet Memes. The University of Arizona, 9, 53-80. http://arizona.openrepository.com/arizona/handle/10150/556817

Denisova, A. (2019). Internet Memes and Society: Social, Cultural, and Political Contexts. In Internet Memes and Society: Social, Cultural, and Political Contexts. Routledge: New York. https://doi.org/10.4324/9780429469404

Eco, U. (1979). The Role of the Reader: Explorations in the Semiotics of Texts. Bloomington: Indiana University Press. https://doi.org/10.1353/phl.1980.0019

Grundlingh, L. (2017). Memes as Speech Acts. Social Semiotics, 28(2), 147-168. https://doi.org/10.1080/10350330.2017.1303020

Halliday, M. A. . (1978). Language as a social semiotic. Edward Arnold.

Jewitt, C. (2013). Multimodal Methods for Researching Digital Technologies. In S. Price, C. Jewitt, \& B. Brown (Eds.), The SAGE Handbook of Digital Technology Research (pp. 250-265). London: Sage.

Jiang, Y., \& Vásquez, C. (2020). Exploring local meaning-making resources A case study of a popular Chinese internet meme (biaoqingbao). Internet Pragmatics, 3(2), 260-282. https://doi.org/10.1075/ip.00042.jia

Johann, M., \& Bülow, L. (2019). One Does Not Simply Create a Meme : Conditions for the Diffusion of Internet Memes. International Journal of Communication, 13, 17201742.

Jones, R. H. (2013). Multimodal Discourse Analysis. The Encyclopedia of Applied Linguistics. https://doi.org/10.1002/9781405198431.wbeal0813

Laksono, D. P., \& Putranti, A. (2016). I Can Haz Stail: a Language Style of Lolcat Meme in Icanhas.Cheezburger.Com. Journal of Language and Literature, 16(01), 70-81. https://doi.org/10.24071/joll.2016.160109

Leeuwen, T. van. (2005). Introducing Social Semiotics. London: Routledge.

Leeuwen, T. van. (2015). Multimodality. In The Handbook of Discourse Analysis (2nd ed.). Wiley Blackwell. https://doi.org/10.4018/978-1-5225-8467-4.ch010

Milner, R. M. (2012). The World Made Meme: Discourse and Identity in Participatory Media. University of Kansas.

Schiffrin, A. (2005). Modelling Speech Acts in Conversational Discourse [The University of Leeds]. http://etheses.whiterose.ac.uk/1332/

Scollon, R., \& LeVine, P. (2004). Multimodal Discourse Analysis as the Confluence of Discourse and Technology. In P. LeVine \& R. Scollon (Eds.), Discourse and Technology: Multimodal Discourse Analysis (pp. 1-6). Washington, DC: Georgetown University Press. https://doi.org/10.1017/s0272263105390280 
Searle, J. R. (2002). Speech Acts, Mind and Social Reality. In Speech Acts, Mind and Social Reality: Discussions with John R. Searle. Dordrecht: Kluwer Academic.

Sebeok, T. A. (2001). Signs: An introduction to semiotics. In Journal of Pragmatics (Second, Vol. 26, Issue 4). London: University of Toronto Press. https://doi.org/10.1016/03782166(96)82062-5

Shifman, L. (2014). Memes in Digital Culture. Cambridge, MA: MIT Press.

Vásquez, C., \& Aslan, E. (2021). "Cats be Outside, How about Meow": Multimodal Humor and Creativity in an Internet Meme. Journal of Pragmatics, 171, 101-117. https://doi.org/10.1016/j.pragma.2020.10.006

Wahyuningsih, W., \& Nirmala, D. (2020). Perlocutionary Act of Euphemism in Indonesian Presidential Election Debate 2019. Indonesian Journal of EFL and Linguistics, 5(1), 113-127. https://doi.org/10.21462/ijefl.v5i1.230

Wiggins, B. E. (2019). The Discursive Power of Memes in Digital Culture: Ideology, Semiotics, and Intertextuality. In The Discursive Power of Memes in Digital Culture. https://doi.org/10.4324/9780429492303-2

Yule, G. (2006). The Study of Language (3rd ed.). New York: Cambridge University Press.

Yus, F. (2019). Multimodality in Memes: A Cyberpragmatic Approach. In Analyzing Digital Discourse: New Insights and Future Directions (Issue October, pp. 105-132). Switzerland: Palgrave McMillan. https://doi.org/10.1007/978-3-319-92663-6 